\title{
Critical Pedagogy and the Resisting Intellectual Part II
}

\author{
Henry A. Giroux
}

Miami University

In "Intellectual Labor and Pedagogical Work: Rethinking the Role of Teacher as Intellectual," (P+P Vol. 3, No. 1), I argued that there is a growing loss of power among teachers around the basic conditions of their work and that this has been accompanied by a wider ideological shift among the public regarding their role as reflective practitioners. I tried to show that teacher work is being increasingly situated within a technical and social division of labor that reduces teachers to the dictates of experts removed from the context of the classroom and serves to widen the political gap between those who control the schools and those who actually deal with curricula and students on a day-to-day basis. Ideologies at work in defining teachers as technicians (as individuals reduced to implementing curricula and methods rather than producing and conceptualizing their own curriculum within specific settings) are evident in teacher education programs, the mass production of teacher proof curricula texts and programs, and in the current discourse on educational reform. I further argued that it is necessary to rethink the nature of teacher work by viewing teachers as intellectuals. The category of intellectual is useful in the following ways: in providing a theoretical basis for examining teacher work as a form of intellectual labor; in clarifying the ideological and material conditions necessary for intellectual work; and in helping to illuminate the various modes of intelligibility, ideologies, and social and political interests that are produced and legitimated by teacher work.

In his attempt to turn the issue of the nature and role of the intellectual into a political question, Antonio Gramsci provides a more helpful theoretical elaboration on this issue. For Gramsci, all men and women are intellectuals, but not all of them function in society as intellectuals. Gramsci is worth quoting at length on this issue:

When one distinguishes between intellectuals and non-intellectuals, one is referring in reality only to the immediate social function of the professional category of the intellectuals, that is, one has in mind the direction in which their specific professional activity is weighted, whether towards intellectual elaboration or towards muscular-nervous effort. This means that, although one can speak of intellectuals, one cannot speak of non-in- 
tellectuals, because non-intellectuals do not exist. But even the relationship between efforts of intellectual-cerebral elaboration and muscularnervous effort is not always the same, so that there are varying degrees of specific intellectual activity. There is no human activity from which every form of intellectual participation can be excluded: homo faber cannot be separated from homo sapiens. Each man[sic], finally, outside his professional activity, carries on some form of intellectual activity, that is, he is a "philosopher," an artist, a man of taste, he participates in a particular conception of the world, has a conscious line of moral conduct, and therefore contributes to sustain a conception of the world or to modify it, that is, to bring into being new modes of thought.'

For Gramsci, all people are intellectuals in that they think, mediate, and adhere to a specific view of the world. The point here, as mentioned previously, is that varying degrees of critical and common-sense thought is endemic to what it means to be human. The significance of this insight is that it gives pedagogical activity an inherently political quality. For instance, Gramsci's view of political activity was deeply rooted in the task of raising the quality of thought of the working class. At the same time, by arguing that all people do not function in their social capacity as intellectuals, Gramsci provides the theoretical groundwork for analyzing the political role of those intellectuals who had to be considered in terms of the organizational and directive functions they performed in a given society.

In the broadest sense, Gramsci attempts to locate the political and social function of intellectuals through his analyses of the role of conservative and radical organic intellectuals. For Gramsci, conservative organic intellectuals provide the dominant class with forms of moral and intellectual leadership. As agents of the status quo, such intellectuals identify with the dominant relations of power and become the propagators of its ideologies and values. This group represents a stratum of intellectuals that gives ruling classes a homogeneity and awareness of their economic, political, and social functions. In the advanced industrial countries organic intellectuals can be found in all strata of society and include specialists in industrial orgnizations, professors in universities, journalists in the culture industry, and various levels of executives in middle management positions.

Radical intellectuals (drawn primarily from a group Gramsci identifies as "traditional intellectuals") also attempt to provide the moral and intellectual leadership of a specific class: in this case, the working class. More specifically, radical organic intellectuals provide the pedagogical and political skills that are nec- 
essary to raise political awareness in the working class in order to help the members of that class to develop leadership skills and to engage in collective struggle. ${ }^{2}$

Gramsci's categories are helpful in that they illuminate the political nature of intellectual work within specific social functions. Moreover, Gramsci's analysis helps to shatter the myth that the nature of intellectual work is determined by one's class location. On the contrary, there is no immediate correspondence between class location and consciousness; but there is a correspondence between the social function of one intellectual's work and the particular relationship it has to modifying, challenging, or reproducing the dominant society. In other words, it is the political nature of intellectual work that is the issue at hand. In my mind, this is a major theoretical advance over the ongoing debate among Marxists and others as to whether intellectuals constitute a specific class or culture. ${ }^{3}$ Furthermore, by politicizing the nature of intellectual work, Gramsci strongly challenges dominant theoretical traditions that have decontextualized the role that intellectuals play in education and the larger society. In other words, he criticizes those theorists who decontextualize the intellectual by suggesting that he or she exists independently of issues of class, culture, power, and politics. Inherent in such a view is the notion that the intellectual is obligated to engage in a value free discourse, one that necessitates that he or she refuses to take sides on different issues, or refuses to link knowledge with the fundamental principles of emancipation. Such a view reinforces the idea that intellectuals are free floating and detached in the sense that they perform a type of labor that is objective and apolitical.

Similarly, Gramsci's notion that intellectuals represent a social category and not a class raises important questions as to how educators might be viewed at different levels of schooling in terms of their politics, the nature of their discourse, and the pedagogical functions they perform. But Gramsci's terms need to be expanded in order to grasp the changing nature and social function of intellectuals in their capacities as educators. The categories around which I want to analyze the social function of educators as intellectuals are: a) resisting intellectuals, b) critical intellectuals, c) accomodating intellectuals, and d) hegemonic intellectuals. It is imperative to note that these are somewhat exaggerated, ideal-typical categories whose purpose is to bring into bold relief the cluster of integrated elements that point to the interests and tendencies to which they refer. Needless to say, there are teachers who move in and out and between these categories and defy being placed in any one of them; moreover, it is conceivable that teachers under different cir- 
cumstances may opt out of one tendency and move into another category. Finally these categories are irreducible to any one specific political doctrine. They point to forms of ideology and social practice that could be taken up by any number of diverse political positions or world views.

\section{Resisting Intellectuals}

Resisting intellectuals is a category that suggests that teachers as intellectuals can emerge from and work with any number of groups, other than and including the working class, that advance emancipatory traditions and cultures within and outside of alternative public spheres. ${ }^{4}$ Utilizing the language of critique, resisting intellectuals employ the discourse of self-criticism so as to make the foundations for a critical pedagogy explicit while simultaneously illuminating the relevance of the latter for both students and the larger society. Central to the category of resisting intellectuals is the task of making the pedagogical more political and the political more pedagogical. In the first instance, this means inserting education directly into the political sphere by arguing that schooling represents both a struggle for meaning and a struggle over power relations. Thus schooling becomes a central terrain where power and politics operate out of a dialectical relationship between individuals and groups who function within specific historical conditions and structural constraints as well as within cultural forms and ideologies that are the basis for contradictions and struggles. Within this view of schooling, critical reflection and action become part of a fundamental social project to help students develop a deep and abiding faith in the struggle to overcome injustices and to humanize themselves. Knowledge and power are inextricably linked in this case to the presupposition that to choose life, so as to make it possible, is to understand the preconditions necessary to struggle for it.

In the second instance, making the pedagogical more political means utilizing forms of pedagogy that treat students as critical agents, problematizing knowledge, utilizing dialogue, and making knowledge meaningful so as to make it critical in order to make it emancipatory. In part, this suggests that resisting intellectuals take seriously the need to give students an active voice in their learning experiences; it means developing a critical vernacular that is attentive to problems experienced at the level of everyday life, particularly as these are related to pedagogical experiences connected to classroom practice. As such, the starting point pedagogically for such intellectuals is not with the isolated student but with collective actors in their various cultural, class, racial, historical, and gendered settings, along with the particularity of their diverse problems, hopes, and dreams. It is 
at this point that the language of critique unites with the language of possibility. That is, resisting intellectuals must take seriously the need to come to grips with those ideological and material aspects of the dominant society that attempt to separate the issues of power and knowledge, which means working to create the ideological and material conditions in both schools and the larger society that give students the opportunity to become agents of civic courage, citizens who have the knowledge and courage to take seriously the need to make despair unconvincing and hope practical. In short, the language of critique unites with the language of possibility when it points to the conditions necessary for new forms of culture, alternative social practices, new modes of communication and a practical vision for the future.

\section{Critical Intellectuals}

Critical intellectuals are ideologically oppositional but do not see themselves as connected either to a specific social formation or as performing a general social function that is expressively political in nature. Their protests constitute a critical function, which they see as part of thcir professional status or obligation as intellectuals. In most cases, the posture of critical intellectuals is self-consciously "apolitical," and their relationship to the rest of society is best defined as free-floating. ${ }^{5}$ As individuals they are critical of inequality and injustice, but they refuse to move beyond their isolated posture to the terrain of collective solidarity and struggle. Often this retreat from politics is justified on the basis of arguments that posit the impossibility of politics for reasons as ideologically diverse as the claim that we live in a totally administered society, or that history is in the hands of a technology out of control, or the simple refusal to believe that human agency has any effect on history.

\section{Accommodating Intellectuals}

Accommodating intellectuals generally stand firm within an ideological posture and set of material practices that supports the dominant society and its ruling groups. Such intellectuals are generally not aware of this process in that they do not define themselves as self-conscious agents of the status quo, even though their politics further the interests of the dominant classes. These intellectuals also define themselves in terms that suggest that they are free floating, removed from the vagaries of class conflicts and partisan politics. But in spite of such rationalizations, they function primarily to produce and mediate uncritically ideas and social practices that serve to reproduce the status quo. These are the intellectuals who decry politics while simultaneously refusing to take risks. Another more subtle variation is the intellectual who disdains politics by pro- 
claiming professionalism as a vague value system, one which often entails the spurious concept of scientific objectivity.

\section{Hegemonic Intellectuals}

Hegemonic intellectuals do more than surrender to forms of academic and political incorporation or hide behind spurious claims to objectivism. They self-consciously define themselves through the forms of moral and intellectual leadership they provide for dominant groups and classes. This stratum of intellectuals provides various factions of the dominant classes with a homogeneity and awareness of their economic, political, and ethical functions. The interests that define the conditions as well as the nature of their work are tied to the preservation of the existing order. Such intellectuals are to be found on the consulting lists of major foundations, on the faculties of major universities as managers of the culture industry, and, in spirit at least, in teaching positions at various levels of schooling.

For fear of these categories appearing to be too rigid, it is important to stress more specifically that the teachers who occupy them cannot be viewed merely from the perspective of the ideological interests they represent. For instance, as Erik Olin Wright has pointed out, the positions that teachers hold must also be analyzed in terms of the objective antagonisms they experience as intellectuals who occupy contradictory class locations. ${ }^{6}$ That is, like workers they have to sell their labor power and have no control over the educational apparatus as a whole. On the other hand, unlike workers they do have some control over the nature of their labor process, i.e., what to teach, how to teach, what kind of research to do, etc. Needless to say, the relative autonomy that teachers have at different levels of schooling differs, with those in higher education having the most autonomy. Moreover, regardless of the ideological interests such teachers represent, there is always the possibility for real tensions and antagonisms between the lack of control they have over the goals and purposes of schooling and the relative autonomy they enjoy. For example, in a time of economic crisis, teachers have been laid off, given increased course loads, denied tenure, and forced to implement administratively dictated pedagogies. It is within these tensions and objective contradictions that the possibilities exist for shifting alliances and movement among teachers from one category to the next.

\section{The Discourse and Role of Educators As Resisting Intellectuals}

In order to fight for schools as democratic public spheres, it is imperative to understand the contradictory roles that resisting intellectuals occupy within the various levels of schooling. In the 
most immediate sense, the notion of resisting intellectual makes visible the paradoxical position that radical educators face in the public schools and in the universities. On the one hand, such intellectuals earn a living within institutions that play a fundamental role in producing the dominant culture. On the other hand, they define their political terrain by offering to students forms of alternative discourse and critical social practices whose interests are often at odds with the overall hegemonic role of the schools and the society it supports. The paradox is not easy to resolve and often represents a struggle against being incorporated by the university or school system through its efforts to reward those educators willing to either remove critical scholarship from their teaching or to remove it from any relation to concrete political movements. At the university level, there is enormous pressure, for example, for radical educators to peddle their academic wares merely as viable commodities for academic journals and conferences. Under the banner of accountability, teachers at all levels of schooling are sometimes subtly and sometimes not so subtly pressured to respond to the issues, modes of research, discourse, and social practices deemed legitimate by the dominant culture. Erik Olin Wright is worth quoting on this issue:

(Radical) theorists within ... universities are under tremendous pressures to ask questions structured by bourgeois problems, bourgeois ideological and political practices. Such pressures are often extremely direct, taking the form of tenure criteria, blacklisting, harassment, etc. But often the pressures are quite subtle, played out through the intellectual debates within professional conferences and journals. To publish in the proper journals one has to ask questions which those journals see as relevant, and such relevance is dictated not by the centrality of the questions to [radical social theory and practice], but to the dilemmas and problems within bourgeois social science. ${ }^{\top}$

Rather than surrender to this form of academic and political incorporation, it is important for educators to make clear the theoretical elements that give meaning to the role of the resisting intellectual as well as to the type of critical educational theory in which such a role is grounded. One starting point would be to define the role of the resisting intellectual around what I have referred to earlier as the discourse of critique and the discourse of possibility.

By employing these discourses, resisting intellectuals can make clear the manner in which power functions in schools in both a negative and positive way. Power is viewed in this instance as both a negative and positive force; its character is dialectical and its mode of operation is always more than simply repressive. 
In other words, domination is never so complete that power is experienced exclusively as a negative force. On the contrary, it means that power is the basis of all forms of behavior in which people resist, struggle, and fight for their image of a better world. What is essential is to understand how power is manifested in schools within the contradictory forms that it takes. One important pedagogical task that emerges from this perspective is to interrogate how knowledge, language, and power come together within the formal and hidden curricula of schools so as to actively silence people.

For instance, rather than viewing knowledge as objective, as merely something to transmit to students, teachers can demonstrate how it is constructed through a selected process of emphasis and exclusion. Such an interrogation could be analyzed around questions such as the following:

What counts as school knowledge?

How is such knowledge selected and organized?

What are the underlying interests that structure the form and content of school knowledge?

How is what counts as school knowledge transmitted?

How is access to such knowledge determined?

What cultural values and formations are legitimated by dominant forms of school knowledge?

What cultural formations are disorganized and delegitimated by dominant forms of school knowledge?

There is also the central issue of making clear the role that language and power have at all levels of schooling. Language must be viewed as more than a tool for merely displaying thought; nor can it be reduced to issues that are technical and developmental in nature. In this case, resisting intellectuals can provide critical analyses of language as linguistic practices which embody forms of power and authority. If language itself is seen as a locus of meaning, it becomes possible to raise questions about the authority patterns that legitimate and utilize language in order to allocate resources and power to some groups while denying them to others. Central to this position is the notion that language practices can only be understood in terms of their articulation with the power relations that structure the wider society. In other words, language as both the subject and object of power represents, in part, an embattled epistemological terrain on which different social groups struggle over how reality is to be signified, reproduced, and resisted. Foucault captures this issue in the following comment:

Education may well be ... the instrument whereby every individual, in a society like our own, can gain access to any kind of discourse. But we all know that in its distribution, in what it permits and what it prevents, it 
follows the well-trodden battle lines of social conflict. Every education system is a political means of maintaining or of modifying the appropriation of discourse ... What is an educational system after all, if not the ritualization of the word; if not a qualification of some fixing roles for speakers; if not the distribution and an appropriation of discourse, with all its learning and its powers? ${ }^{8}$

The point here is that institutionally legitimated language practices introduce teachers and students to specific questions, specific ways of life, and are constitutive of specific social relations. By establishing a relationship between language and power, it is possible for teachers to interrogate specific language practices around the questions they raise, the incapacitating silences they harbor, and how the latter bear down on students in the form of impositions that disorganize and delegitimate certain experiences and ideas. Such a view of language points to more than the need for teachers and students alike to deconstruct its hidden codes and meanings; it is also imperative for them to develop alternative rhetorical structures and discursive practices which both challenge and affirm forms of thinking, speaking, and acting that support a critical pedagogy.

The relationship between power, on the one hand, and knowledge and language on the other, needs to be supplemented with an understanding of how power works on the structure of the personality and the body so as to promote certain forms of learning. More specifically, the latter points to how educators can address the issue of how learning takes place outside of the realm of mediated consciousness and rationality. For instance, how is it possible to understand learning as a function of habit, as part of the fabric of ongoing social practices that become part of what might be called sedimented histories? Put another way, how is it possible for teachers to understand how learning is mediated and produced through the unconscious so as to promote forms of behavior that represent an active refusal to listen, to hear, or to engage in activities that might threaten one's world view, or in some cases, even to affirm one's own possibilities. Of course, this issue raises serious questions about how schools through various rituals, social practices, and rules become implicated in forms of domination that bear down on the body and psyche, that "penetrate" the body in order to locate it in a grid of technologies and practices that serve to anchor in it specific ideologies and values conducive to the larger society.

The other side of this view of learning, one that engages the discourse of possibility, is that if needs can be constructed, they can be unmade and reconstructed in the interests of emancipatory concerns. For example, for teachers to simply explain the ideology of sexism in order to teach students about how it oppresses women and denigrates men, may be meaningless if students have internalized such an ideology as part of the habits and structure of their psyche 
and personality. As a constellation of needs, sexism becomes a material force that has to be reflected upon and reconstructed through new social practices and experiences lived concretely within nonsexist classroom relations. At stake here is the notion that if creativity and talent are largely a function of social conditions, it is important to unravel how ideology as a set of ideas and a material practice in both the overt curriculum and in those aggressively engendered silences that make up the hidden curriculum either block or promote forms of critical teaching and learning.

All of these aspects of schooling suggest the need for teachers to be more critically attentive to the ideologies embedded in the hidden curriculum and how they work to shape different aspects of school life. American educational theory has always posited a slavish attachment to that which could be seen and observed in classroom life; this emphasis on the literal has been a formidable obstacle in preventing teachers and others from looking beyond the immediacy of the classroom events to that which is unspoken and unseen so as to probe deeper into the meanings, values, and ideologies at work in all aspects of school life. ${ }^{9}$

Another central task for resisting intellectuals is to investigate the relation of popular and subordinate cultures to the dominant modes of schooling. This means investigating school cultures as a set of activities which are lived and developed within asymmetrical relations of power. Culture in this case is seen as a form of production whose processes are intimately connected with the structuring of different social formations, particularly those that are related to gender, age, race, and class. Culture is not merely a warehouse of knowledge forms, social practices, and values to be accumulated, stored, and transmitted to students. Such a view of culture refuses to engage institutionalized and dominant culture as a selected and privileged discourse that can function to legitimate specific interests and groups.

Culture must be fully implicated and understood as part of the terrain of politics and power. In this view, culture can be analyzed as a form of production through which human beings attempt to mediate everyday life through their use of language and other material resources. Most importantly, culture is viewed in this sense as a sphere of struggle and contradictions, and it must be seen in a real sense as unfinished, as part of an ongoing struggle for individuals and groups to define and affirm their histories and place in the world. In a non-reductionist sense, culture is a form of praxis that has a dialectical quality that is manifested in cultural forms and practices that can serve either dominating or emancipatory interests. As a form of domination, the dominant culture serves actively to silence subordinate cultures. As an emancipatory form, culture is a concrete expression of the ways in which people affirm, resist, de- 
sire, and struggle to re-present themselves as human agents establishing their rightful place in the world.

As part of a critical theory of education, this suggests that resisting intellectuals argue for a notion of cultural power that takes as its starting point the social and historical particularities of the students with whom they work. This means working with the experiences that students, adults, and other learners bring to schools and other educational sites. It means making these experiences in their public and private forms the object of confirmation and debate. It also means legitimating such experiences in order to investigate how they become constitutive of social reality. By affirming the cultural capital that gives meaning to students' lives, resisting intellectuals can help to establish the pedagogical conditions in which such students display an active voice and presence. Such an approach also points to the pedagogical conditions necessary to critically engage the languages, dreams, values, and encounters of those students whose histories are often actively silenced. In this instance, cultural power refers to the need to work with and on such experiences. It also means engaging other cultural experiences and forms of knowledge as part of the need to critically appropriate them so as to help students gain the skills, values, and sense of responsibility they need to be creative, critical, and ethical citizens.

Finally, it is imperative for resisting intellectuals to form alliances among themselves, to engage in a critical dialogue with other teachers in the schools, and to work with oppositional groups willing to fight for a qualitatively better life for all. In the first instance, teachers and academics who function as resisting intellectuals can collectively organize in order to engage in projects designed to understand the critical role that educators play at all levels of schooling in producing and legitimating existing social relations. This might take the form of establishing social projects in which teachers critically interrogate existing school curricula, the hidden curricula, policy formation at the local and state levels, the form and content of school texts, and the working conditions that characterize specific schools. Not only would such projects provide a theoretical and political service by critically engaging the nature of school life, they would also give teachers the opportunity to begin to communicate with each other about their common concerns.

Furthermore, such alliances provide the possibility for university and public school people to redefine the traditional theory-practice relationship. This means abolishing the pernicious institutionalized social division of labor between those who do theory at the university level and those who merely apply it at the elementary, middle, and secondary school levels. One step in this direction is for resisting intellectuals from these different spheres to forge alliances around common social and political projects in which they share their theo- 
retical concerns and practical talents. At stake here is the recognition that these different educational sites give rise to various forms of theoretical production and discourse, and that such sites cannot be seen as separate places for the development of theory and the implementation of practice.

Such projects also have value because they open the possibility for resisting intellectuals to develop and work with movements outside of the limiting contours of academic disciplines, symposiums, and reward systems that have become the traditional referents for intellectual activity. One benefit of working outside of the university and school system is that resisting intellectuals can organize their work around concrete issues and problems that point to different forms of accountability. Such relations provide the opportunity for teachers to broaden and examine the political nature of their work, to reflect on the theories they employ, and to constantly interrogate the questions they ask and the methods they use, particularly as these relate to emancipatory concerns. In effect, I am arguing that teachers as resisting intellectuals need to become a movement marked by an active involvement in democratic public spheres in which the primacy of the political is asserted anew. Resisting intellectuals can join with any number of social groups engaged in forms of emancipatory struggle. For example, by linking up with ecology, feminist, peace and neighborhood groups, resisting intellectuals can bring their skills and talents to bear on vital forms of engagement at the local level, e.g., local based efforts against toxic waste dumping, nuclear power, consumer fraud, racial and sexual discrimination, etc. Within this context, the political becomes pedagogical. In other words, intellectuals learn from and with others engaged in similar political struggles.

Such alliances are absolutely necessary if teachers, particularly within the public schools, are to be able to bring outside force to bear on fighting for ideological and material conditions within the schools that will allow them to function as intellectuals. Teachers need to operate within conditions that will allow them to reflect, read, share their work with others, produce curriculum materials, and publish their achievements for others outside of their local schools. At the present time, teachers labor in the public schools under organizational constraints and ideological conditions that leave them little room for collective work and critical pursuits. Their teaching hours are too long, they are generally isolated in cellular structures and have few opportunities to teach with others, and they have little say over the selection, organization, and distribution of teaching materials. Moreover, they operate under class loads and within an industrial timetable that is oppressive. Their salaries in the United States are a matter of scandal that is only now being fully recognized by the American public. The issue, of course, is that intellectual work needs to be supported by practical conditions 
buttressed by concomitant democratic ideologies. By fighting for conditions that support joint teaching, collective writing and research, and democratic planning, teachers will make inroads into opening up new spaces for creative and reflective discourse and action. The importance of such a discourse cannot be overstressed. For within such a discourse teachers can develop a radical pedagogy that relates language and power, takes popular experience seriously as part of the learning process, combats mystification, and helps students to reorder the raw experiences of their lives through the perspectives opened up by history, philosophy, sociology, and other related disciplines. Through such a discourse, resisting intellectuals can elaborate a language of possibility, one that proposes extensive philosophic and programmatic changes in education, on the one hand, while giving new meaning to the pedagogical and political necessity of creating the conditions for emancipatory forms of self and social empowerment among both teachers and students on the other.

It is important to stress that we live at a time when the experience and language of democracy are in danger. Under such conditions, the role of the resisting intellectual represents both the call for new forms of pedagogy and the construction of a social movement aimed at the development of a society founded on the project of radical democracy. Resisting intellectuals, in this instance, need to negate the totalitarian dimensions of the dominant order and work collectively with others to develop a language in which a radical imagination points to alternative public spheres where the principles of freedom and justice provide the foundation of schooling and everyday life. The utopian nature of this project is tempered and made concrete, not only because it is important for the left and others to recognize that history is open to change, but more importantly, to recognize that if we don't act soon our children may have no future.

\section{Notes}

1. Antonio Gramsci, Selections from the Prison Notebooks, Ed. and Trans. Q. Hoare and G. Smith (New York: International Publishers, 1971).

2. Ibid.

3. For an overview of this debate, see Carl Boggs, Marxism and the role of intellectuals, New Political Science 1:(2/3) 1979, pp.7-23.

4. Gramsci, op. cit.; Paulo Freire, The politics of education (South Hadley, MA.: Bergin and Garvey Publishers, 1984).

5. The concept of the free-floating intellectual as used here is similar to that expressed by Karl Mannheim, Ideology and Utopia (New York: Harvest Book, 1936).

6. Erik Olin Wright, Intellectuals and the working class, The insurgent sociologist, 8:1 (Winter 1978), pp. 5-18.

7. Ibid., p 16. 
8. Foucault, cited in Henry A. Giroux, Theory and resistance in education (South Hadley, MA.: Bergin and Garvey Publishers, 1983), p. 207.

9. Giroux, Theory and resistance in education, op. cit. 